\title{
Radical-Mediated Hetaryl Functionalization of Nonactivated Alkenes through Distal ipso-Migration of O- or S-Hetaryls
}

\author{
Huihui Zhanga \\ Meishan Ji \\ Youhao Wei \\ Haodong Chen ${ }^{\mathrm{a}}$ \\ Xinxin $\mathbf{W u}^{\mathbf{a}}$ \\ Chen Zhu*a,b (D) \\ a Key Laboratory of Organic Synthesis of Jiangsu Province, College of \\ Chemistry, Chemical Engineering and Materials Science, Soochow \\ University, 199 Ren-Ai Road, Suzhou, Jiangsu 215123, P. R. of China \\ chzhu@suda.edu.cn \\ b Key Laboratory of Synthetic Chemistry of Natural Substances, \\ Shanghai Institute of Organic Chemistry, Chinese Academy of \\ Sciences, 345 Lingling Road, Shanghai 200032, P. R. of China \\ Dedicated to llhyong Ryu on the occasion of his $70^{\text {th }}$ birthday \\ Published as part of the Cluster Radicals - by Young Chinese Organic Chemists
}

\section{Received: 15.08 .2020}

Accepted after revision: 21.09 .2020

Published online: 30.10 .2020

DOI: 10.1055/s-0040-1705968; Art ID: st-2020-10452-c

Abstract A radical-mediated hetaryl functionalization of nonactivated alkenes through distal ipso-migration of O- or S-containing hetaryls was developed. Furyl, benzofuryl, thienyl, and benzothienyl groups showed satisfactory migratory abilities. A variety of heteroatom-centered radicals, including azido, trifluoromethylsulfanyl, and silyl radicals readily trigger the migration cascade, and a new $\mathrm{C}$-heteroatom and C$\mathrm{C}$ bond are concomitantly constructed in the reaction. This method provides an efficient approach to the synthesis of high-valued complex O- or S-hetaryl compounds.

Key words hetaryl compounds, alkene difunctionalization, functional-group migration, radical reaction, radicals, rearrangement

Alkenes are important products of the petrochemical industry, and are also bulk chemicals extensively used in synthetic chemistry. Consequently, the utilization of alkenes represents a long-term research interest of chemists. Radical-mediated difunctionalization of alkenes provides an efficient approach for alkene utilization through concomitant incorporation of two extra functional groups, leading to a diversity of polyfunctionalized products. ${ }^{1}$ However, the state-of-the-art methods largely depend on the properties of alkenes. Activated alkenes such as styrenes or acrylates are generally suitable substrates by virtue of a $p-\pi$ conjugate effect that can stabilize nascent radical species. In contrast, functionalization of aliphatic alkenes, which are not activated, remains challenging.

Remote functional-group migration is an ingenious tactic for achieving the elusive radical-mediated difunctionalization of nonactivated alkenes. ${ }^{2}$ We and others have systematically showcased the migratory aptitudes of various groups, including cyano, ${ }^{3}$ hetaryl, ${ }^{4}$ oximino, ${ }^{4,5}, 5$ carbonyl, ${ }^{5 a, 6}$
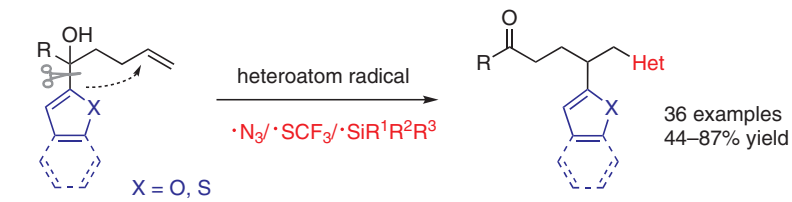

Addition of heteroatom radicals $\mathrm{O}$ Formation of $\mathrm{C}-\mathrm{Het}$ and $\mathrm{C}-\mathrm{C}$ bonds

alkynyl, ${ }^{7}$ and alkenyl groups. ${ }^{8}$ In particular, a range of $\mathrm{N}$ containing five- and six-membered hetaryls readily migrate, triggered by extrinsic radicals, to give the corresponding hetaryl functionalized products. These findings prompted us to investigate further the feasibility of migration of $\mathrm{O}$ - or S-hetaryls, and we recently developed a fluoroalkyl-radical-triggered remote $\mathrm{O}$ - or S-hetaryl migration. ${ }^{9}$ To explore the generality of this protocol, we examined the hetaryl functionalization of nonactivated alkenes by a heteroatom-radical-promoted remote O- or S-hetaryl migration (Scheme 1). Intramolecular migrations of furyl, benzofuryl, thienyl, and benzothienyl groups readily proceeded in the presence of various heteroatom-centered radicals, including azido, trifluoromethylsulfanyl, and silyl radicals. New C-heteroatom and C-C bonds were simultaneously constructed in the reaction. This approach offers a significant complement to the well-studied N-hetaryl migration.

$$
\begin{gathered}
\text { A. Functional-group-migration-based alkene difunctionalization } \\
\text { MG (migratory group) }=\begin{array}{c}
\text { cyano, (het)aryl, oximino, } \\
\text { carbonyl, alkynyl, alkenyl }
\end{array}
\end{gathered}
$$

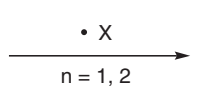

B. This work: O- or S-containing hetaryl migration
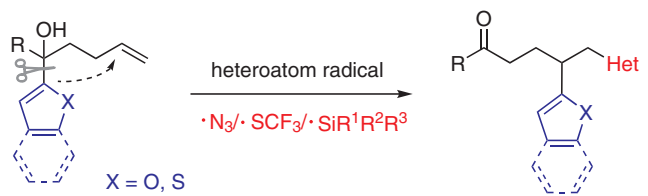

Addition of heteroatom radicals

Formation of $\mathrm{C}-\mathrm{Het}$ and $\mathrm{C}-\mathrm{C}$ bonds

Scheme 1 Radical difunctionalization of nonactivated alkenes through distal functional-group migration 
Azides often serve as privileged precursors for the synthesis of amines and other nitrogen-containing compounds. Moreover, azides are widely used as versatile building blocks and synthetic intermediates in medicinal chemistry and in chemical biology. ${ }^{10,11}$ Radical azidohetarylation of nonactivated alkenes offers an efficient approach for the rapid assembly of complex aliphatic azides, which are otherwise hard to synthesize. By using O- or S-hetaryl-substituted tertiary alcohols $\mathbf{1}$ as substrates, the migration of the hetaryl moiety was triggered by the addition of an azido radical, generated by the interaction of (diacetoxyiodo)benzene (PIDA) and TMSN ${ }_{3}$, affording the corresponding hetaryl and ketone-functionalized alkyl azides $\mathbf{2}$ in synthetically useful yields (Scheme 2). ${ }^{12}$ Both electron-rich and electron-deficient tertiary alcohols were suitable substrates. The reaction outcomes were not obviously affected by substitution at the para-, meta-, or ortho-position of the aryl group. Notably, the examples $\mathbf{2} \mathbf{f}$ and $\mathbf{2 g}$ showed that the benzofuryl group has superior migratory ability to that of a benzothiazolyl or thiazolyl group; the resultant benzofuryl-migrated products were obtained in ten times the yields of the (benzo)thiazolyl-migrated products. Moreover,
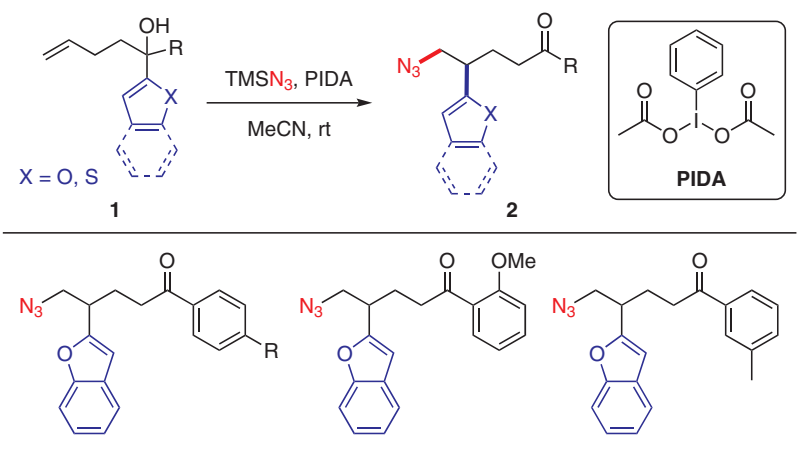

$\begin{array}{ll}\text { 2a, } \mathrm{R}=\mathrm{H}, & 62 \%, 2 \mathrm{~h} \\ \text { 2b, } \mathrm{R}=\mathrm{Me}, & 66 \%, 3 \mathrm{~h}\end{array}$ $2 \mathrm{~b}, \mathrm{R}=\mathrm{Me}, \quad 66 \%, 3 \mathrm{~h}$
$\mathbf{2 c}, \mathrm{R}=\mathrm{OCF}_{3}, 60 \%, 2 \mathrm{~h}$

2d, $74 \%, 2 \mathrm{~h}$

2e, $79 \%, 3 \mathrm{~h}$
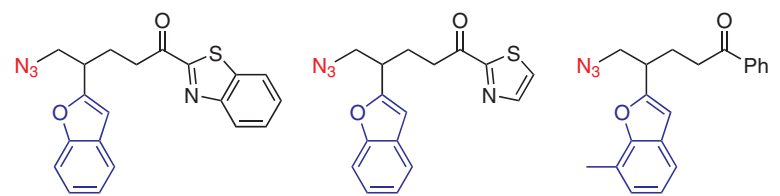

2f, $54 \%, 3 \mathrm{~h}$

2g, $84 \%, 3$ h

2h, $83 \%, 3 \mathrm{~h}$

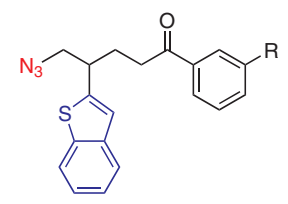

2i, $\mathrm{R}=\mathrm{H}, \quad 69 \%, 2 \mathrm{~h}$

$2 \mathrm{j}, \mathrm{R}=\mathrm{Me}, \quad 51 \%, 3 \mathrm{~h}$<smiles>[R]c1ccc(C(=O)CCC(CN)c2cccs2)cc1</smiles><smiles>NCC(CCC(=O)c1ccccc1)c1ccc(Cl)s1</smiles>

2k, $\mathrm{R}=\mathrm{H}, \quad 45 \%, 3 \mathrm{~h}$

2l, $\mathrm{R}=\mathrm{OMe}, \quad 46 \%, 3 \mathrm{~h}$

$2 \mathrm{~m}, 53 \%, 7 \mathrm{~h}^{\mathrm{a}}$

Scheme 2 Azidohetarylation of nonactivated alkenes. Reagents and conditions: 1 ( 0.2 mmol, 1.0 equiv), TMSN ${ }_{3}$ ( 0.8 mmol, 4.0 equiv), PIDA ( 0.4 mmol, 2.0 equiv), $\mathrm{CH}_{3} \mathrm{CN}(2.0 \mathrm{~mL})$, rt. Yields of the isolated products are reported. a $\mathrm{A}$ second batch of $\mathrm{TMSN}_{3}$ ( 1 equiv) and PIDA (0.5 equiv) was added after $6 \mathrm{~h}$. benzothienyl and thienyl groups also displayed good migratory aptitudes under the reaction conditions, leading to useful yields of the corresponding products $\mathbf{2 i}-\mathbf{m}$.

Owing to the high lipophilicity of trifluoromethylsulfanyl group, bioactive molecules containing this group usually exhibit improved metabolic stability and transmembrane permeation. ${ }^{13}$ To test the generality of our protocol, it was applied to the trifluoromethylthiolative hetarylation of nonactivated alkenes triggered by the addition of an $\mathrm{F}_{3} \mathrm{CS}$ radical. A set of representative examples are shown in Scheme 3. The transformation readily took place to afford the desired $\mathrm{SCF}_{3}$-functionalized ketones $3 .^{14}$ The electronic effects and positions of the substituents on the aryl and benzofuryl groups had little impact on the reaction outcome (3a-e). Remarkably, the competitive migration between two different hetaryls [benzofuryl vs. pyridyl; benzofuryl vs. (benzo)thiazolyl] showed exclusive chemoselectivities, in that only the benzofuryl-migrated products $\mathbf{3 f}-\mathbf{h}$ were obtained in the reaction. Furthermore, benzothienyl and thienyl also showed satisfactory migratory abilities, readily furnishing the hetaryl-migrated products $\mathbf{3 i}-\mathbf{1}$. Note that furyl-substituted tertiary alcohols were unsuitable
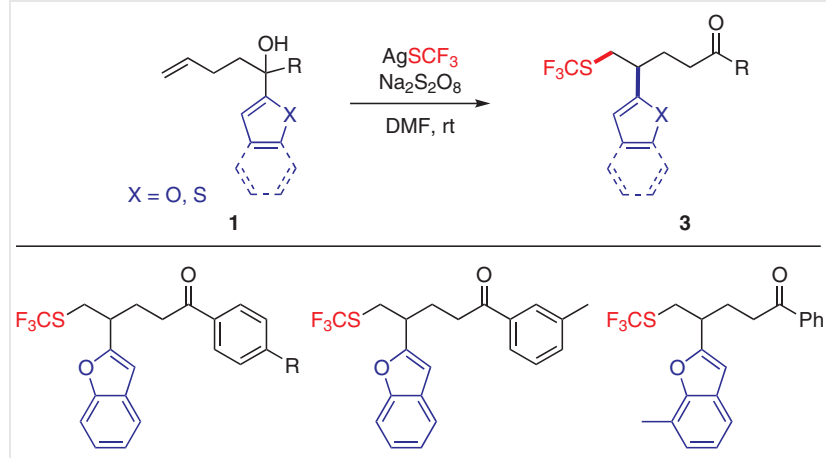

3a, $\mathrm{R}=\mathrm{H}, \quad 78 \%, 3 \mathrm{~h}$

3b, $\mathrm{R}=\mathrm{Ph}, 87 \%, 5 \mathrm{~h}$

3c, $R=F, \quad 56 \%, 5 h$

3d, $80 \%, 4 \mathrm{~h}$

3e, $73 \%, 4 \mathrm{~h}$

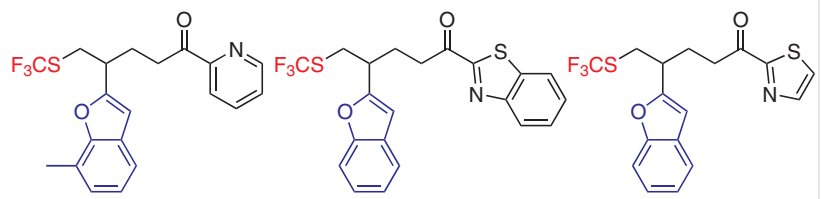

3f, $63 \%, 4 \mathrm{~h}$

3g, $49 \%, 5 \mathrm{~h}$

3h, 36\%, 3 h

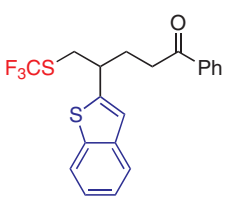

$3 i, 63 \%, 4 \mathrm{~h}$

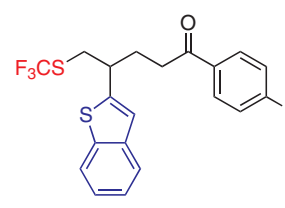

3j, $\mathrm{R}=\mathrm{OMe}, 47 \%, 5 \mathrm{~h}$ $3 \mathbf{k}, \mathrm{R}=\mathrm{OCF}_{3}, 71 \%, 4 \mathrm{~h}$
Scheme 3 Trifluoromethylthiolative hetarylation of nonactivated alkenes. Reagents and conditions: 1 ( 0.2 mmol, 1.0 equiv), $\mathrm{AgSCF}_{3}(0.3$ mmol, 1.5 equiv), and $\mathrm{Na}_{2} \mathrm{~S}_{2} \mathrm{O}_{8}(0.6 \mathrm{mmol}, 3.0$ equiv), DMF $(2 \mathrm{~mL})$, rt. Yields of the isolated products are reported. 


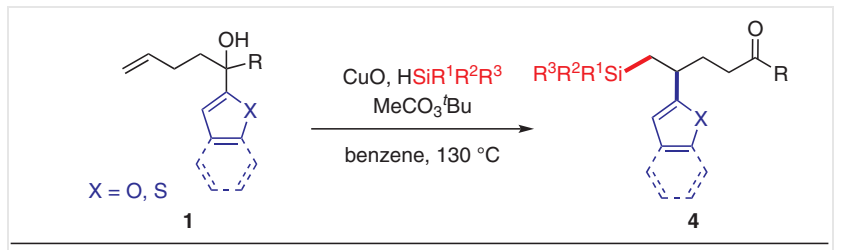

(n)

$\begin{array}{ll}\text { 4a, } 59 \%, 17 \mathrm{~h} & \begin{array}{l}\text { 4b, } \mathrm{R}=\mathrm{F}, \\ \mathbf{4 c}, \mathrm{R}=\mathrm{Ph}, 76 \%, 17 \mathrm{~h}\end{array} \quad \mathbf{4 d}, 79 \%, 18 \mathrm{~h}\end{array}$

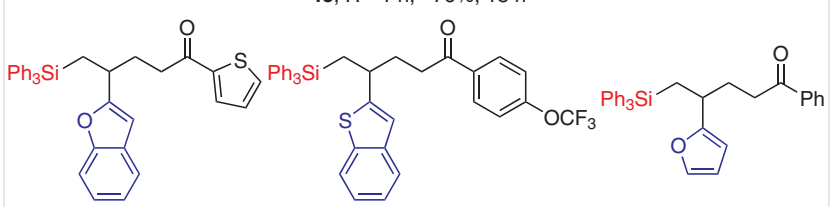

$4 e, 63 \%, 17 \mathrm{~h} \quad 4 \mathbf{4 f}, 62 \%, 17 \mathrm{~h} \quad \mathbf{4 g}, 46 \%, 17 \mathrm{~h}$

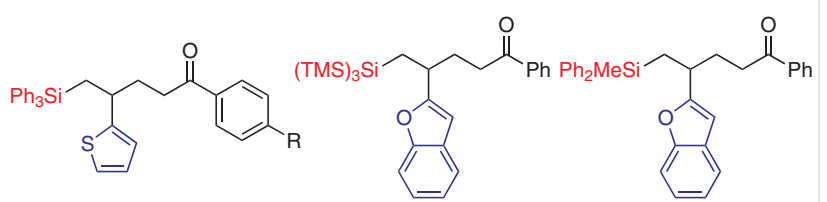

4h, $\mathrm{R}=\mathrm{H}, \quad 48 \%, 17 \mathrm{~h}$ $4 \mathrm{i}, \mathrm{R}=\mathrm{Me}, 50 \%, 18 \mathrm{~h}$

$4 \mathbf{j}, 84 \%, 17 \mathrm{~h}$

$4 \mathbf{k}, 63 \%, 17 \mathrm{~h}$

Scheme 4 Silylhetarylation of nonactivated alkenes. Reagents and conditions: 1 ( $0.2 \mathrm{mmol}, 1.0$ equiv), silane ( $1.0 \mathrm{mmol}, 5.0$ equiv), tert-butyl peroxyacetate ( $0.8 \mathrm{mmol}, 4.0$ equiv), $\mathrm{CuO}(0.02 \mathrm{mmol}, 10 \mathrm{~mol} \%)$, DMAP $\left(0.05 \mathrm{mmol}, 0.25\right.$ equiv), benzene $(2 \mathrm{~mL}), 130^{\circ} \mathrm{C}$, sealed tube. Yields of the isolated products are reported.

substrates, probably due to their decomposition under the oxidative conditions.

Organosilicon compounds have extensive applications in several interdisciplinary fields spanning materials science, polymer development, energy chemistry, and drug synthesis. ${ }^{15,16}$ Consequently, the construction of C-Si bonds is one of the most important topics in synthetic chemistry. The concomitant introduction of a silyl group and a hetaryl group onto an olefin can provide valuable polyfunctionalized silicon compound with high product diversity. In the presence of a copper-salt catalyst and a peroxy ester, the radical silylhetarylation of tertiary alcohols 1 with triphenylsilane $\left(\mathrm{Ph}_{3} \mathrm{SiH}\right)$ as source of silyl radicals proceeded readily to afford the desired ketone products 4 (Scheme 4 ). ${ }^{17}$ The exclusive formation of $\mathbf{4 e}$ indicated that the benzofuryl group has a better migratory ability than that of a thienyl group. In addition to benzofuryl, other O- or S-hetaryls, including benzothienyl, furyl, and thienyl groups, also migrated to the $\gamma$-position, leading to the corresponding products $\mathbf{4 f - i}$ in moderate yields

Furthermore, tris(trimethylsilyl)silane (TTMSS) and methyl(diphenyl)silane $\left(\mathrm{Ph}_{2} \mathrm{SiHMe}\right)$ also proved to be suitable sources of silyl radicals, affording the alkyl silanes $\mathbf{4} \mathbf{j}$ and $\mathbf{4 k}$, whereas phenylsilane $\left(\mathrm{PhSiH}_{3}\right)$ was not a suitable substrate for the transformation.

On the basis of the experimental results and our knowledge of radical-mediated functional-group migration, ${ }^{2 \mathrm{f}}$ we propose the mechanism shown in Scheme $5 .{ }^{18}$ The addition of an external radical $\mathbf{Y}$ to compound $\mathbf{1}$ generates alkyl radical a. Intramolecular capture of the alkyl radical a by the hetaryl compound via a five-membered transition state, followed by cleavage of a cyclic $\mathrm{C}-\mathrm{C}$ bond of intermediate $\mathbf{b}$ affords the ketyl radical $\mathbf{c}$. Single-electron oxidation of $\mathbf{c}$ gives d, and subsequent deprotonation furnishes the final product.

To demonstrate the synthetic utility of our reaction, we chose to transform the azidohetarylated product $\mathbf{2 a}$ into other valuable molecules (Scheme 6). First, 2a was readily converted into the tetrahydropyridine 5 in $91 \%$ yield under Staudinger reaction conditions. Moreover, 2a was a suitable substrate for a click reaction, reacting with ethynylbenzene to give the corresponding triazole 6 in $97 \%$ yield. ${ }^{19}$ Benzotriazole $\mathbf{7}$ was obtained by the reaction of $\mathbf{2 a}$ with benzyne, generated in situ. ${ }^{20}$

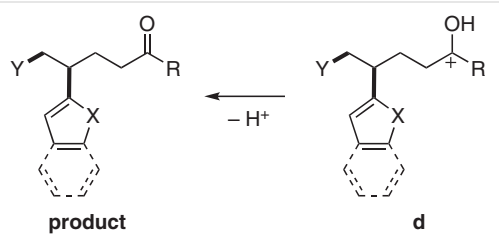

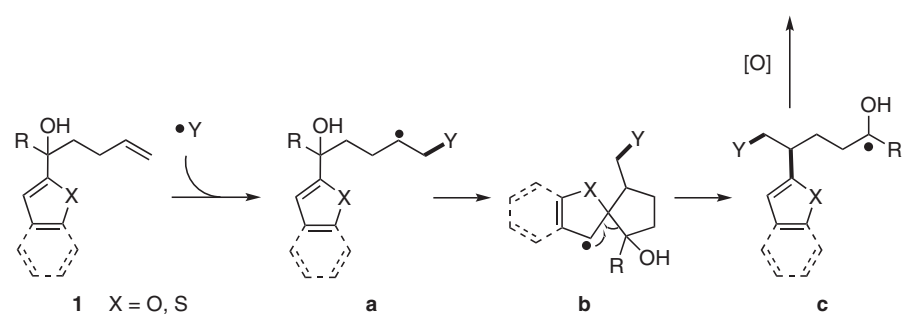

Scheme 5 Proposed mechanism 


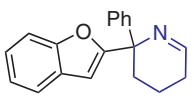

5 (91\%)<smiles>CCOC(C)C(C)Oc1ccccc1</smiles>

2a

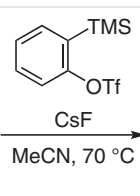

$\stackrel{\mathrm{CN}, 70^{\circ} \mathrm{C}}{\longrightarrow}$<smiles>O=C(CCC(Cn1nnc2ccccc21)c1cc2ccccc2o1)c1ccccc1</smiles>

$$
\mathrm{Ph}=\mid \begin{gathered}
\mathrm{CuSO}_{4} \\
\mathrm{Na} \text { ascorbate } \\
{ }_{\mathrm{B}} \mathrm{BuOH} / \mathrm{H}_{2} \mathrm{O}, \mathrm{rt}
\end{gathered}
$$<smiles>O=C(CCC(Cn1cc(-c2ccccc2)nn1)c1cc2ccccc2o1)c1ccccc1</smiles>

$6(97 \%)$

Scheme 6 Synthetic applications

In summary, we have developed a heteroatom-centered radical-mediated hetaryl functionalization of nonactivated alkenes. The transformation proceeds through the remote migration of O- or S-hetaryls, including benzofuryl, furyl, benzothienyl, and thienyl. Many heteroatom-centered radicals, such as azido, trifluoromethylsulfanyl, and silyl radicals, promote the migration process and are readily incorporated into alkenes along with the construction of new chemical bonds, e.g. $\mathrm{C}-\mathrm{N}, \mathrm{C}-\mathrm{S}$, and $\mathrm{C}-\mathrm{Si}$ bonds. The product can be further converted into other synthetically valuable molecules. This protocol provides a complement to current knowledge regarding $\mathrm{N}$-hetaryl migration.

\section{Funding Information}

C.Z. is grateful for the financial support from the National Natural Science Foundation of China $(21722205,21971173)$ and the Priority Academic Program Development of Jiangsu Higher Education Institutions (PAPD).

\section{Supporting Information}

Supporting information for this article is available online at https://doi.org/10.1055/s-0040-1705968.

\section{References and Notes}

(1) For selected reviews on radical-mediated difunctionalization of alkenes, see: (a) Cao, M.-Y.; Ren, X.; Lu, Z. Tetrahedron Lett. 2015, 56, 3732. (b) Clark, A. J. Eur. J. Org. Chem. 2016, 2016, 2231. (c) Kindt, S.; Heinrich, M. R. Synthesis 2016, 48, 1597. (d) Chen, Z.-M.; Zhang, X.-M.; Tu, Y.-Q. Chem. Soc. Rev. 2015, 44, 5220. (e) Zeng, Y.; Ni, C.; Hu, J. Chem. Eur. J. 2016, 22, 3210.

(2) For selected reviews on radical-mediated functional-group migration, see: (a) Studer, A.; Bossart, M. Tetrahedron 2001, 57, 9649. (b) Wu, X.; Wu, S.; Zhu, C. Tetrahedron Lett. 2018, 59, 1328. (c) Li, W.; Xu, W.; Xie, J.; Yu, S.; Zhu, C. Chem. Soc. Rev.
2018, 47, 654. (d) Sivaguru, P.; Wang, Z.; Zanoni, G.; Bi, X. Chem. Soc. Rev. 2019, 48, 2615. (e) Wu, X.; Zhu, C. Chin. J. Chem. 2019, 37, 171. (f) Wu, X.; Zhu, C. Acc. Chem. Res. 2020, 53, 1620.

(3) For selected examples of cyano migration, see: (a) Wu, Z.; Ren, R.; Zhu, C. Angew. Chem. Int. Ed. 2016, 55, 10821. (b) Wang, N.; Li, L.; Li, Z.-L.; Yang, N.-Y.; Guo, Z.; Zhang, H.-X.; Liu, X.-Y. Org. Lett. 2016, 18, 6026. (c) Ji, M.; Wu, Z.; Yu, J.; Wan, X.; Zhu, C. Adv. Synth. Catal. 2017, 359, 1959. (d) Ren, R.; Wu, Z.; Huan, L.; Zhu, C. Adv. Synth. Catal. 2017, 359, 3052. (e) Ji, M.; Wu, Z.; Zhu, C. Chem. Commun. 2019, 55, 2368.

(4) For selected examples of hetaryl migration, see: (a) Wu, Z; ; Wang, D.; Liu, Y.; Huan, L.; Zhu, C. J. Am. Chem. Soc. 2017, 139, 1388. (b) Wang, M.; Wu, Z.; Zhang, B.; Zhu, C. Org. Chem. Front. 2018, 5, 1896. (c) Chen, D.; Wu, Z.; Yao, Y.; Zhu, C. Org. Chem. Front. 2018, 5, 2370. (d) Zhang, H.; Wu, X.; Zhao, Q.; Zhu, C. Chem. Asian J. 2018, 13, 2453. (e) Tang, N.; Yang, S.; Wu, X.; Zhu, C. Tetrahedron 2019, 75, 1639. (f) Yu, J.; Wu, Z.; Zhu, C. Angew. Chem. Int. Ed. 2018, 57, 17156. (g) Liu, J.; Wu, S.; Yu, J.; Lu, C.; Wu, Z.; Wu, X.; Xue, X.-S.; Zhu, C. Angew. Chem. Int. Ed. 2020, 59, 8195.

(5) (a) Yu, J.; Wang, D.; Xu, Y.; Wu, Z.; Zhu, C. Adv. Synth. Catal. 2018, 360, 744. (b) Chen, D.; Ji, M.; Yao, Y.; Zhu, C. Acta Chim. Sinica (Engl. Ed.) 2018, 76, 951. (c) Wang, N.; Wang, J.; Guo, Y.; Li, L.; Sun, Y.; Li, Z.; Zhang, H.-X.; Guo, Z.; Li, Z.-L.; Liu, X.-Y. Chem. Commun. 2018, 54, 8885.

(6) (a) Li, Z.-L.; Li, X.-H.; Wang, N.; Yang, N.-Y.; Liu, X.-Y. Angew. Chem. Int. Ed. 2016, 55, 15100. (b) Wang, M.; Li, M.; Yang, S.; Xue, X.-S.; Wu, X.; Zhu, C. Nat. Commun. 2020, 11, 672.

(7) For selected examples of alkynyl migration, see: (a) Xu, Y.; Wu, Z.; Jiang, J.; Ke, Z.; Zhu, C. Angew. Chem. Int. Ed. 2017, 56, 4545. (b) Tang, X.; Studer, A. Chem. Sci. 2017, 8, 6888. (c) Tang, N.; Shao, X.; Wu, X.; Zhu, C. Acta Chim. Sinica (Engl. Ed.) 2019, 77, 922. (d) Wang, M.; Zhang, H.; Liu, J.; Wu, X.; Zhu, C. Angew. Chem. Int. Ed. 2019, 58, 17646.

(8) For selected examples of alkenyl migration, see: (a) Tang, X.; Studer, A. Angew. Chem. Int. Ed. 2018, 57, 814. (b) Li, L.; Li, Z.-L.; Gu, Q.-S.; Wang, N.; Liu, X.-Y. Sci. Adv. 2017, 3, e1701487. (c) Wu, S.; Wu, X.; Wang, D.; Zhu, C. Angew. Chem. Int. Ed. 2019, $58,1499$.

(9) Zhang, H.; Kou, L.; Chen, D.; Ji, M.; Bao, X.; Wu, X.; Zhu, C. Org. Lett. 2020, 22, 5947. 
(10) For selected reviews, see: (a) Brase, S.; Gil, C.; Knepper, K.; Zimmermann, V. Angew. Chem. Int. Ed. 2005, 44, 5188. (b) Brase, S.; Banert, K. Organic Azides: Syntheses and Applications; Wiley: Chichester, 2010. (c) Lapointe, G.; Kapat, A.; Weidner, K.; Renaud, P. Pure Appl. Chem. 2012, 84, 1633.

(11) For selected reviews, see: (a) Lebel, H.; Leogane, O.; Huard, K.; Lectard, S. Pure Appl. Chem. 2006, 78, 363. (b) Lang, S.; Murphy, J. A. Chem. Soc. Rev. 2006, 35, 146. (c) Köhn, M.; Breinbauer, R. Angew. Chem. Int. Ed. 2004, 43, 3106. (d) Sletten, E. M.; Bertozzi, C. R. Acc. Chem. Res. 2011, 44, 666.

(12) 5-Azido-4-(1-benzofuran-2-yl)-1-phenylpentan-1-one (2a); Typical Procedure

Tertiary alcohol 1a ( $0.2 \mathrm{mmol}, 1.0$ equiv), PIDA ( $0.4 \mathrm{mmol}, 2.0$ equiv) were loaded into a flame-dried reaction vial that was subjected to three cycles of evacuation and flushing with $\mathrm{N}_{2}$. $\mathrm{CH}_{3} \mathrm{CN}(2.0 \mathrm{~mL})$ was added to the mixture from a syringe, and $\mathrm{TMSN}_{3}(0.8 \mathrm{mmol}, 4.0$ equiv) was added dropwise. The mixture was then stirred at $25{ }^{\circ} \mathrm{C}$ until the starting material was consumed (TLC). The mixture was extracted with EtOAc $(3 \times 10$ $\mathrm{mL}$ ), and the organic solvent was removed under vacuum. The residue was purified by flash column chromatography [silica gel, EtOAc-PE (30:1)] to give a yellow oil; yield: $39.7 \mathrm{mg}$ (62\%). FTIR: 3063, 2925, 2854, 1717, 1521, 1455, 1353, 1254, 1225 $\mathrm{cm}^{-1} .{ }^{1} \mathrm{H}$ NMR $\left(400 \mathrm{MHz}, \mathrm{CDCl}_{3}\right): \delta=7.92-7.84(\mathrm{~m}, 2 \mathrm{H}), 7.57-$ 7.49 (m, $2 \mathrm{H}), 7.47-7.38$ (m, $3 \mathrm{H}), 7.28-7.19$ (m, $2 \mathrm{H}), 6.57$ (s, 1 $\mathrm{H})$, 3.76-3.68 (m, $1 \mathrm{H}), 3.67-3.58(\mathrm{~m}, 1 \mathrm{H}), 3.29-3.19(\mathrm{~m}, 1 \mathrm{H})$, $3.00(\mathrm{t}, J=7.2 \mathrm{~Hz}, 2 \mathrm{H}), 2.34-2.14(\mathrm{~m}, 2 \mathrm{H}) .{ }^{13} \mathrm{C}$ NMR $(100 \mathrm{MHz}$, $\left.\mathrm{CDCl}_{3}\right): \delta=199.2,157.3,154.8,136.7,133.2,128.6,128.3,128.0$, 124.0, 122.8, 120.7, 111.1, 104.4, 54.5, 39.2, 35.7, 25.3. HRMS (ESI): $m / z[\mathrm{M}+\mathrm{Na}]^{+}$calcd for $\mathrm{C}_{19} \mathrm{H}_{17} \mathrm{~N}_{3} \mathrm{NaO}_{2}: 342.1213$; found: 342.1213

(13) For selected reviews, see: (a) Biomedical Aspects of Fluorine Chemistry; Filler, R.; Kobayashi, Y., Ed.; Kodansha: Tokyo, 1982. (b) Becker, A. Inventory of Industrial Fluoro-Biochemicals; Eyrolles: Paris, 1996. (c) Leroux, F.; Jeschke, P.; Schlosser, M. Chem. Rev. 2005, 105, 827. (d) Mantear, B.; Pazenok, S.; Vorsand, J.-P.; Leroux, F. R. J. Fluorine Chem. 2010, 131, 140.

(14) 4-(1-Benzofuran-2-yl)-1-phenyl-5-[(trifluoromethyl)sulfanyl]pentan-1-one (3a); Typical Procedure

Tertiary alcohol $\mathbf{1 a}\left(0.2 \mathrm{mmol}, 1.0\right.$ equiv), $\mathrm{AgSCF}_{3}(0.3 \mathrm{mmol}, 1.5$ equiv), and $\mathrm{Na}_{2} \mathrm{~S}_{2} \mathrm{O}_{8}(0.6 \mathrm{mmol}, 3.0$ equiv) were loaded into a flame-dried reaction vial that was subjected to three cycles of evacuation and flushing with $\mathrm{N}_{2}$. $\operatorname{DMF}(2.0 \mathrm{~mL})$ was added to the mixture from a syringe, and the mixture was stirred at $25{ }^{\circ} \mathrm{C}$ until the starting material was consumed (TLC). The mixture was then extracted with EtOAc $(3 \times 10 \mathrm{~mL})$, and the combined organic extracts were washed with brine, dried $\left(\mathrm{MgSO}_{4}\right)$, filtered, and concentrated. The residue was purified by flash column chromatography [silica gel, EtOAc-PE (30:1)] to give a white solid; yield: $78.7 \mathrm{mg}$ (87\%); $\mathrm{mp} 93-94^{\circ} \mathrm{C}$.

FTIR: 3676, 2988, 2970, 1792, 1671, 1636, 1522, 1436, 1374 $\mathrm{cm}^{-1} \cdot{ }^{1} \mathrm{H}$ NMR $\left(400 \mathrm{MHz}, \mathrm{CDCl}_{3}\right): \delta=7.91-7.81(\mathrm{~m}, 2 \mathrm{H}), 7.57-$ 7.49 (m, $2 \mathrm{H}), 7.47-7.37$ (m, $3 \mathrm{H}), 7.29-7.20(\mathrm{~m}, 2 \mathrm{H}), 6.55$ (d, $J=$ $0.8 \mathrm{~Hz}, 1 \mathrm{H}), 3.38-3.26(\mathrm{~m}, 3 \mathrm{H}), 2.98(\mathrm{t}, J=7.2 \mathrm{~Hz}, 2 \mathrm{H}), 2.42-$ $2.33(\mathrm{~m}, 1 \mathrm{H}), 2.27-2.17(\mathrm{~m}, 1 \mathrm{H}) .{ }^{13} \mathrm{C}$ NMR $\left(100 \mathrm{MHz}, \mathrm{CDCl}_{3}\right)$ : $\delta=198.9,157.0,154.9,136.6,133.2,131.0\left(\mathrm{q}, J_{\mathrm{C}-\mathrm{F}}=304.3 \mathrm{~Hz}\right)$, 128.6, 128.1, 128.0, 124.1, 122.9, 120.8, 111.1, 104.8, 39.3, 35.8, $33.7\left(\mathrm{q}, J_{\mathrm{C}-\mathrm{F}}=1.9 \mathrm{~Hz}\right), 27.1 .{ }^{19} \mathrm{~F}$ NMR $\left(376 \mathrm{MHz}, \mathrm{CDCl}_{3}\right): \delta=-41.2$ (s). HRMS (ESI): $m / z[\mathrm{M}+\mathrm{Na}]^{+}$calcd for $\mathrm{C}_{20} \mathrm{H}_{17} \mathrm{~F}_{3} \mathrm{NaO}_{2} \mathrm{~S}$; 401.0794; found: 401.0793 .

(15) For selected reviews, see: (a) Brook, M. Silicon in Organic, Organometallic and Polymer Chemistry; Wiley: New York, 2000. (b) Silicon Containing Polymers: The Science and Technology of Their Synthesis and Applications; Jones, R. G.; Ando, W.; Chojnowski, J., Ed.; Springer Netherlands: Dordrecht, 2000. (c) The Chemistry of Organic Silicon Compounds; Rappoport, Z.; Apeloig, Y., Ed.; Wiley: Chichester, 1997. (d) Bio-Inspired SiliconBased Materials; Zelisko, P. M., Ed.; Springer Netherlands: Dordrecht, 2014.

(16) For selected reviews, see: (a) Chatgilialoglu, C. Chem. Rev. 1995, 95, 1229. (b) Oestreich, M. Angew. Chem. Int. Ed. 2016, 55, 494. (c) Shang, X. J.; Liu, Z.-Q. Org. Biomol. Chem. 2016, 14, 7829.

(17) 4-(1-Benzofuran-2-yl)-1-phenyl-5-(triphenylsilyl)pentan-1one (4a); Typical Procedure

Tertiary alcohol 1 a $\left(0.2 \mathrm{mmol}, 1.0\right.$ equiv), $\mathrm{Ph}_{3} \mathrm{SiH}$ (1.0 mmol, 5.0 equiv), tert-butyl peroxyacetate ( $0.8 \mathrm{mmol}, 4.0$ equiv, $50 \mathrm{wt} . \%$ in mineral spirit), CuO (0.02 mmol, $10 \mathrm{~mol} \%$ ), and DMAP (0.05 mmol, 0.25 equiv) were loaded into a sealed tube which was subjected to three cycles of evacuation and flushing with $\mathrm{N}_{2}$. Benzene $(2 \mathrm{~mL})$ was added to the mixture, the tube was sealed, and the mixture was stirred at $130^{\circ} \mathrm{C}$ until the starting material was consumed (TLC). The organic solvent was removed under vacuum, and the residue was purified by flash column chromatography [silica gel, EtOAc-PE (30:1)] to give a colorless oil; yield: $62.5 \mathrm{mg}(59 \%)$.

FTIR: 3068, 3011, 2922, 1772, 1684, 1455, 1428, 1363, 1253, $1219 \mathrm{~m}^{-1} .{ }^{1} \mathrm{H}$ NMR $\left(400 \mathrm{MHz}, \mathrm{CDCl}_{3}\right): \delta=7.80-7.72(\mathrm{~m}, 2 \mathrm{H})$, 7.51-7.45 (m, $7 \mathrm{H}), 7.38-7.34(\mathrm{~m}, 2 \mathrm{H}), 7.34-7.28(\mathrm{~m}, 5 \mathrm{H})$, 7.26-7.22 (m, $6 \mathrm{H}), 7.19-7.10(\mathrm{~m}, 2 \mathrm{H}), 6.10(\mathrm{~s}, 1 \mathrm{H}), 3.28-3.16$ $(\mathrm{m}, 1 \mathrm{H}), 2.84-2.70(\mathrm{~m}, 2 \mathrm{H}), 2.25-2.05(\mathrm{~m}, 3 \mathrm{H}), 1.91-1.83(\mathrm{~m}, 1$ H). ${ }^{13} \mathrm{C}$ NMR $\left(100 \mathrm{MHz}, \mathrm{CDCl}_{3}\right): \delta=199.7,160.9,154.4,136.9$, $135.6,134.6,132.9,129.4,128.5,128.5,128.0,127.8,123.1$, $122.3,120.3,110.9,103.0,36.4,34.9,32.1,19.4$. HRMS (ESI): $\mathrm{m} / z[\mathrm{M}+\mathrm{Na}]^{+}$calcd for $\mathrm{C}_{37} \mathrm{H}_{32} \mathrm{NaO}_{2} \mathrm{Si}$ : 559.2064; found: 559.2068 .

(18) Detailed mechanistic pathways for each reaction are presented in the Supporting Information (Figures S1-S3).

(19) Huang, F.-Q.; Xie, J.; Sun, J.-G.; Wang, Y.-W.; Dong, X.; Qi, L.-W.; Zhang, B. Org. Lett. 2016, 18, 684.

(20) Reddy, B. V. S.; Praneeth, K.; Yadav, J. S. Carbohydr. Res. 2011, 346, 995. 